\title{
Anatomia dos órgãos vegetativos de Hymenaea martiana Hayne (Caesalpinioideae- Fabaceae): espécie de uso medicinal em Caetité-BA
}

\begin{abstract}
SILVA, M.S. ${ }^{1 *}$; LEITE, K.R.B. ${ }^{2}$; SABA, M.D. ${ }^{3}$
${ }^{1}$ Universidade do Estado da Bahia, Programa de Pós-graduação em Biodiversidade Vegetal, Rua da Gangorra 503, CHESF, Alves de Souza, CEP: 48.608-240, Paulo Afonso-Brasil *naalvaa.santos@hotmail.com '2Universidade Federal da Bahia, Instituto de Biologia, Laboratório de Anatomia Vegetal e Identificação de Madeiras (LAVIM), Rua Barão de Jeremoabo, s/n, Campus Universitário de Ondina, CEP: 40170-115, Salvador-Brasil ${ }^{3}$ Universidade do Estado da Bahia, Departamento de Educação, Rodovia Lomanto Júnior s/n, BR 407, km 12, CEP: 48970-000, Senhor do Bonfim-Brasil
\end{abstract}

\begin{abstract}
RESUMO: Hymenaea martiana Hayne (Fabaceae-Caesalpinioideae) apresenta grande valor na medicina popular em Caetité. A casca, entrecasca do caule e a resina, são utilizadas no tratamento de diversos males. Neste estudo são apresentadas a caracterização anatômica e histoquímica dos órgãos vegetativos. Amostras foram coletadas e processadas segundo técnicas usuais em anatomia vegetal e histoquímica. Todos os órgãos apresentam, em visão transversal, epiderme unisseriada e cavidades secretoras. Cutícula espessa ocorre em todos os órgãos aéreos. A raiz é tetrarca. Colênquima lacunar foi encontrado no caule. Bainha de fibras esclerenquimáticas envolve os feixes vasculares dos órgãos aéreos. Células pétreas ocorrem no pecíolo. Tricomas tectores ocorrem em ambas as faces da folha. A folha é hipoestomática com estômatos paracíticos e o mesofilo é dorsiventral. Cristais de oxalato de cálcio ocorrem no caule, pecíolo e lâmina foliar. Compostos fenólicos ocorrem na raiz, pecíolo e nervura central da folha. Grãos de amido ocorrem na raiz, caule e pecíolo. Lipídios ocorrem em todos os órgãos. Acredita-se que compostos fenólicos e cavidades secretoras de resina podem justificar a utilidade medicinal da espécie pela população de Caetité.
\end{abstract}

Palavras-chave: Caesalpinioideae, Hymenaea, Caetité, anatomia, histoquímica

ABSTRACT: Anatomy of vegetative organs of Hymenaea martiana Hayne (FabaceaeCaesalpinioideae): a species of medicinal use in Caetité-Bahia State, Brazil. Hymenaea martiana Hayne (Fabaceae-Caesalpinioideae) shows a great value in folk medicine in Caetité. Its bark, stem-bark and resin are used to treat various ailments. In this study, the anatomical and histochemical characterization of vegetative organs is reported. Samples were collected and processed according to usual techniques of plant anatomy and histochemistry. All organs have, by cross-sectional view, uniseriate epidermis and secretory cavities. Thick cuticle occurs in all aerial organs. The root is tetrarch. Lacunar collenchyma was found in the stem. Sclerenchymatic sheath of fibers surrounds the vascular bundles of the aerial organs. Stone cells occur in the petiole. Trichomes occur on both sides of the leaves. The leaf is hypostomatic with paracytic stomata and the mesophyll is dorsiventral. Calcium oxalate crystals occur in the stem, petiole and leaf blade. Phenolic compounds occur in the root, petiole and midrib of the leaf. Starch grains occur in the root, stem and petiole. Lipids occur in all organs. It is believed that phenolic compounds and resin secretory cavities may justify the use of medicinal species by the population of Caetité.

Key words: Caesalpinioideae, Hymenaea, Caetité, anatomy, histochemistry

\section{INTRODUÇÃO}

Hymenaea L., pertencente à família Fabaceae (Caesalpinioideae), é predominantemente tropical (Lewis, 1987) e caracterizada por apresentar tronco com exsudado resinoso, podendo ser reconhecido por conter folhas bifolioladas, flores grandes com pétalas e frutos robustos, lenhosos e indeiscentes (Queiroz, 2009).

Hymenaea martiana Hayne, conhecida como

Recebido para publicação em 16/05/2011

Aceito para publicação em 16/04/2012

Rev. Bras. PI. Med., Botucatu, v.14, n.4, p.673-679, 2012. 
jatobá, é típica dos biomas cerrado e caatinga (Queiroz, 2009), sendo os representantes utilizados na medicina popular (Silva \& Andrade, 2005), assim como os de outras espécies do gênero (Pasa et al., 2005; Borba \& Macedo, 2006; Souza \& Felfili, 2006; Sambuichi et al., 2009).

Esta espécie, em Caetité, é utilizada no tratamento de diversas enfermidades, de acordo com a população local a casca e entrecasca do caule na forma de xarope e chá são utilizadas no tratamento de problemas respiratórios, inflamações, dores no estômago, no peito, e na coluna, enquanto a resina é utilizada como cicatrizante. Vale ressaltar que para outras espécies do gênero, Langenheim \& Lee (1974), Nogueira et al. (2001) e Barbosa et al. (2007) relataram a presença de compostos terpenóides e flavonóides, importantes no tratamento dessas enfermidades. Devido à ampla utilização de $H$. martiana pela população de Caetité, a análise estrutural da espécie seria uma das primeiras ferramentas a ser utilizada para identificar as estruturas anatômicas responsáveis pela produção dessa resina e a composição química.

A partir do exposto, objetivou-se caracterizar anatômica e histoquimicamente os órgãos vegetativos de $H$. martiana visando identificar quais estruturas anatômicas são responsáveis por secretar e/ou armazenar substâncias ergásticas, cujas atribuições podem ser medicinais, além de fornecer informações úteis para a taxonomia do grupo.

\section{MATERIAL E MÉTODO}

Hymenaea martiana Hayne foi coletada no Distrito de Brejinho das Ametistas, município de Caetité, BA. Ramos férteis foram herborizados (Mori et al., 1985), o material testemunho depositado no Herbário da Universidade do Estado da Bahia (HUNEB-coleção Caetité), sob o número 19841 e identificado por especialista. Folhas adultas foram coletadas e fixadas em FAA $70 \%$ e conservadas em etanol $70 \%$. Sementes coletadas juntamente com o material herborizado foram colocadas para germinar sem nenhum tratamento prévio, e, após três a quatro meses, os órgãos vegetativos foram fixados em FAA $70 \%$ e conservados em etanol $70 \%$.

Em laboratório o material foi seccionado à mão livre com auxílio de lâmina de barbear. Foram realizados cortes transversais da raiz principal e caule da planta jovem; lâmina foliar, pecíolo e cortes paradérmicos da folha da planta adulta. As amostras foram clarificadas em hipoclorito de sódio $10 \%$, lavadas em água destilada, coradas com safranina e azul de astra (9:1) para cortes transversais e apenas safranina para cortes paradérmicos, montadas entre lâminas e lamínulas com glicerina a $50 \%$ ou gelatina glicerinada e seladas com parafina (Macêdo, 1997).
Os testes histoquímicos foram feitos em cortes transversais (raiz, caule, pecíolo e lâmina foliar) e paradérmicos do material fresco utilizando-se ácido sulfúrico diluído para detecção de cristais de oxalato de cálcio; ácido acético diluído para detecção de carbonato de cálcio; cloreto férrico $10 \%$ e carbonato de sódio a $2 \%$ para identificação de compostos fenólicos; lugol para identificação de amido e sudan IV para identificação de lipídios. Para todos os testes realizados foi utilizada a metodologia proposta por Macêdo (1997).

\section{RESULTADO}

Os caracteres anatômicos analisados nas secções paradérmicas e transversais de Hymenaea martiana podem ser observados nas Figuras 1 a 13.

Em secções transversais foi possível observar que a epiderme da raiz é unisseriada, com parênquima cortical formado por células de formato arredondado (Figura 1). A camada mais interna do córtex é formada pela endoderme que contém apenas uma camada de células e internamente a ela observouse o cilindro vascular composto pelo periciclo com cerca de três a quatro camadas de células (Figura 2). Observaram-se cavidades secretoras no córtex externo (Figura 1) e deposição de celulose no cilindro vascular (Figura 2).

O caule, em secção transversal, apresentou superfície ondulada e formato triangular (Figura 3). A epiderme é unisseriada contendo células com formatos variando de arredondado a elíptico e com diferentes diâmetros, recobertas por uma cutícula espessa (Figura 4). O colênquima é lacunar e composto por quatro a cinco camadas celulares (Figura 4). Assim como na raiz, cavidades secretoras ocorreram na região subepidérmica (Figuras 3 e 4 ). Inclusões celulares como cristais prismáticos e drusas foram observados no floema e na camada mais interna do córtex (Figura 4).

Em vista frontal, as células epidérmicas de H. martiana apresentaram paredes espessadas, sinuosas e com diferentes formatos e tamanhos (Figuras 5 e 6), sendo observados ainda tricomas tectores unicelulares distribuídos de forma esparsa apenas na região costal da lâmina foliar (Figura 6), mesmo local de ocorrência dos cristais prismáticos. Os estômatos ocorreram apenas na face abaxial e são do tipo paracítico (Figura 7).

Em secção transversal observou-se cutícula espessa ao longo de toda a lâmina foliar, epiderme unisseriada em ambas as faces, sendo as células epidérmicas de tamanhos e formatos variados com as células da face abaxial, menores em relação às células da face adaxial além da presença de tricomas esparsos e estômatos ao mesmo nível das demais células epidérmicas (Figuras 8 e 9). 

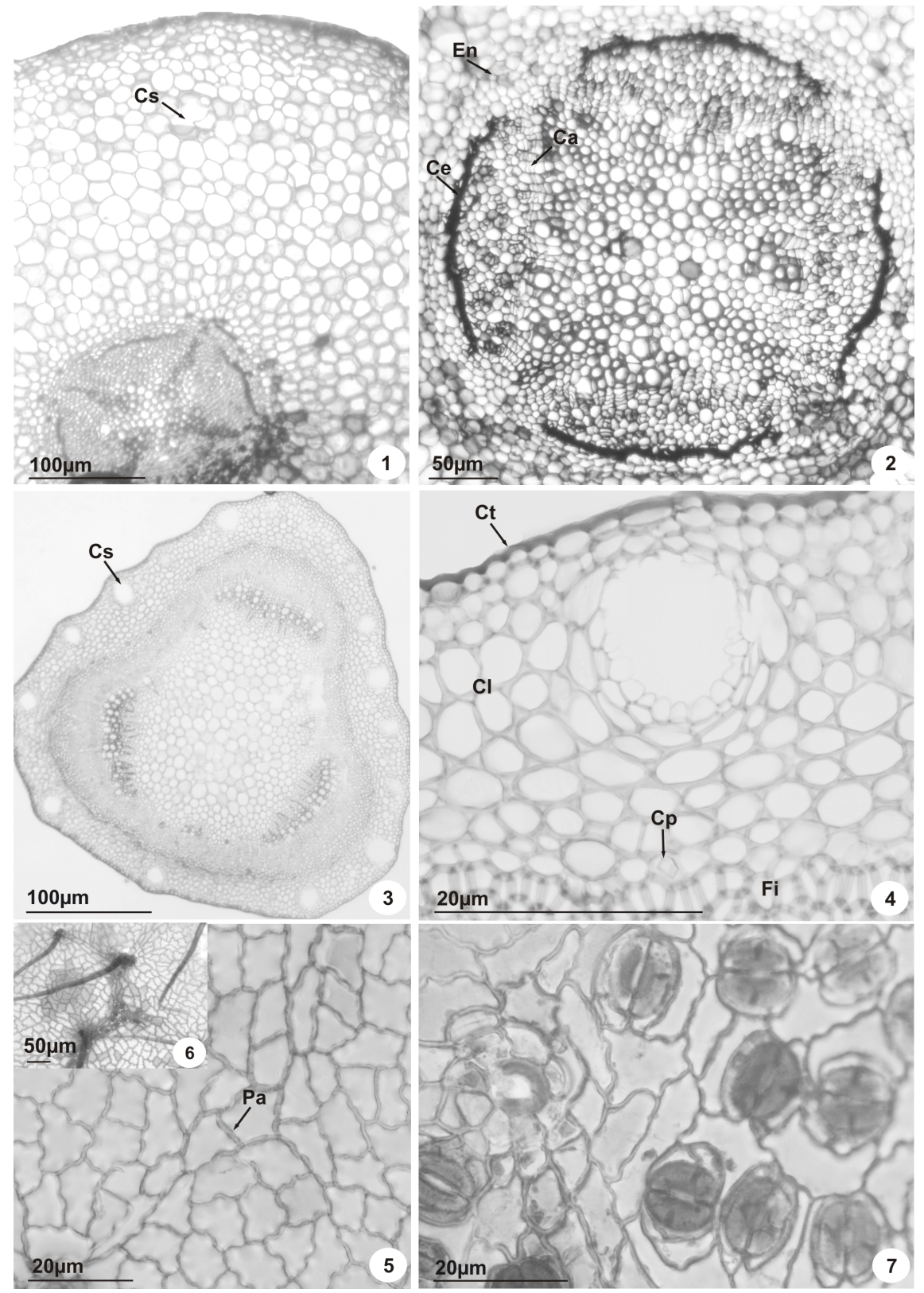

FIGURAS 1-7. Secções transversais do caule e raiz e paradérmicas da folha de Hymenaea martiana Hayne. 1. Vista geral da raiz: cavidade secretora em início de formação (Cs). 2. Detalhe do cilindro vascular: endoderme (En), celulose (Ce) e câmbio (Ca). 3. Aspecto geral do caule: cavidade secretora (Cs). 4. Detalhe do caule: cutícula (Ct), colênquima $(\mathrm{Cl})$, cristal prismático $(\mathrm{Cp})$ e fibras $(\mathrm{Fi})$. 5. Superfície adaxial: Parede espessa $(\mathrm{Pa})$. 6. Superfície adaxial: tricomas tectores. 7. Superfície abaxial: estômatos.

A nervura principal apresentou face adaxial plana e abaxial convexa e a região cortical é formada por cinco a seis camadas de células com parede espessada. A vascularização nessa região é representada por um único feixe central, caracterizado pela presença de floema envolvendo completamente o xilema o qual é circundado por fibras pericíclicas em toda a sua extensão (Figura 8 ). Inclusões celulares do tipo cristal prismático e drusa ocorreram no floema e no xilema e neste último tecido observaram-se fibras intraxilemáticas (Figura 8).
O mesofilo é dorsiventral com parênquima paliçádico formado por duas a três camadas de células alongadas e justapostas enquanto $o$ parênquima lacunoso possui também de duas a três camadas de células mais ou menos alongadas e frouxamente distribuídas (Figura 9). Os feixes vasculares nesta região apresentaram extensão de bainha formada por fibras pericíclicas e endoderme, que se estenderam até a epiderme de ambos os lados (Figura 9), podendo ainda ser observados cristais prismáticos e cavidades secretoras, estas ocorrendo 
imediatamente abaixo da epiderme assim como observado na nervura principal (Figura 8).

O pecíolo em secção transversal apresentou formato cilíndrico, com superfície pouco ondulada, epiderme unisseriada com células variando de ovais a arredondadas, cutícula espessa e tricomas tectores esparsos (Figura 10). O córtex é formado por cerca de oito a 10 camadas de células parenquimáticas, sendo nele observadas cavidades secretoras, tecido de sustentação formado por células pétreas (Figura 12) e células contendo cristais prismáticos (Figura 13), tanto na região cortical externa quanto na interna. O sistema vascular é constituído por feixes caracterizados pela presença de floema envolvendo completamente o xilema e evidenciou-se uma camada descontínua de fibras esclerenquimáticas externamente ao floema (Figuras 10 e 11). No xilema do pecíolo, assim como na nervura mediana, há



FIGURAS 8-13. Secções transversais da lâmina foliar e pecíolo de Hymenaea martiana Hayne. 8. Nervura central: cutícula (Ct), estômato (Est), tricoma (Tr), cavidade secretora (Cs) e fibras intraxilemáticas (Fix). 9. Mesofilo: epiderme adaxial $(E d)$ e abaxial $(E b)$, parênquima paliçádico $(P p)$, parênquima lacunoso $(P I)$, fibras pericíclicas $(\mathrm{Fp})$, endoderme (En). 10. Vista geral do pecíolo: cutícula (Ct), tricoma (Tr) e cavidade secretora (Cs). 11. Vista parcial do pecíolo evidenciando fibras esclerenquimáticas (Fi), fibras intraxilemáticas (Fix). 12. Detalhe do pecíolo evidenciando células pétreas (Cpe). 13. Cristal prismático (Cp) e fibras (Fi). 


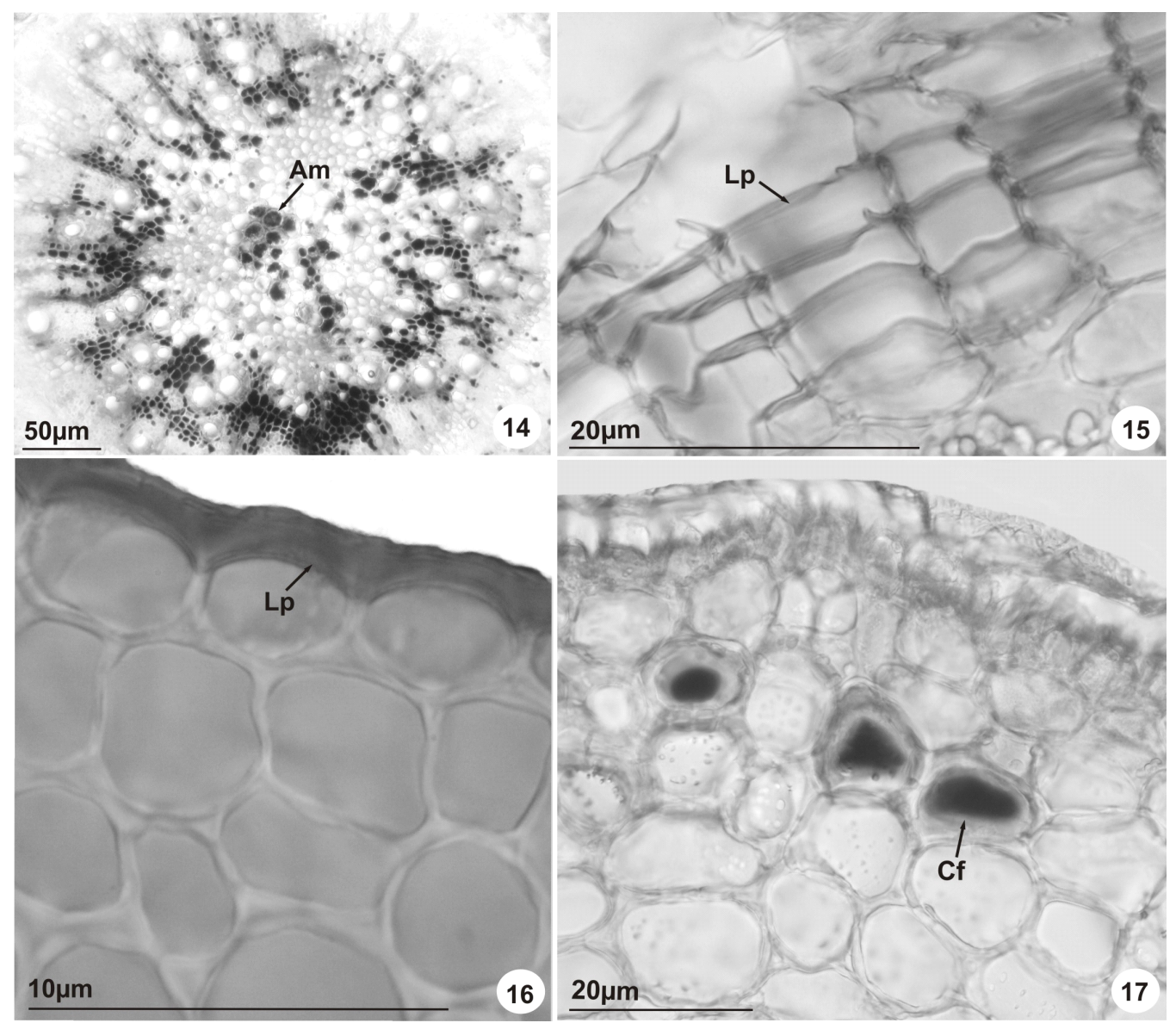

FIGURAS 14-17. Secções transversais da raiz, caule e pecíolo de Hymenaea martiana Hayne submetidas ao teste histoquímico. 14. Raiz: Amido nas células vasculares e na medula (Am). 15. Raiz: Lipídios na periderme (Lp). 16. Caule: lipídios na cutícula (Lp). 17. Pecíolo: Compostos fenólicos nas células corticais (Cf).

presença de fibras intraxilemáticas (Figura 11) e no floema evidenciaram-se cristais prismáticos.

Testes histoquímicos foram realizados com a espécie $H$. martiana em função da ampla utilização dos órgãos vegetativos pela população. O tipo e localização das substâncias apresentadas pela espécie estudada neste trabalho podem ser observados nas figuras 14 a 17.

Grãos de amido, na raiz foram observados na região medular e nas células parenquimáticas do sistema vascular (Figura 14), no caule ocorreram na medula e no pecíolo, evidenciaram-se no córtex e nas células parenquimáticas do floema.

Os lipídios, na raiz, ocorreram na medula e periderme (Figuras 15); no caule, distribuíram-se na cutícula (Figura 16), córtex, células secretoras e floema; no pecíolo, ocorreram na cutícula, córtex, floema e xilema. Na lâmina foliar, os lipídios foram encontrados na cutícula, parênquima paliçádico e lacunoso.

Compostos fenólicos foram encontrados impregnando a parede das células corticais e floemáticas da raiz, pecíolo e nervura central da folha e sob a forma de idioblastos fenólicos na região cortical do pecíolo (Figura 17).

Cristais de oxalato de cálcio foram localizados em células parenquimáticas do caule (Figura 4), pecíolo (Figura 13) e lâmina foliar.

\section{DISCUSSÃO}

A análise dos resultados mostrou que a presença de cutícula espessa observada nos órgãos aéreos, a ocorrência de tricomas, espessamento e sinuosidade de paredes são características relacionadas ao ambiente no qual a planta se encontra servindo como barreira à perda excessiva de água, refletindo a intensa radiação solar a que está submetida e atuando positivamente na diminuição contra o ataque de fungos e bactérias patogênicos (Esau, 1974; Cutter, 1986; Alquini et al., 2006).

A ocorrência de estômatos paracíticos, corrobora os resultados de Metcalfe \& Chalk (1950), que descreveram dois tipos estomáticos para a subfamília Caesalpinioideae, rubiáceo (paracítico) e ranunculáceo (anomocítico). Além disso, observouse que os mesmos se concentram na epiderme 
abaxial, assim como relatado para Hymenaea stilbocarpa (Moreira-Coneglian \& Oliveira, 2006) e Hymenaea courbaril var. stilbocarpa descrita por Jorge et al. (2006).

O mesofilo dorsiventral em $H$. martiana é uma característica que difere do tipo relatado por Metcalfe \& Chalk (1950) para as espécies do gênero Hymenaea, estes autores descreveram para o gênero mesofilo isobilateral. Em $\mathrm{H}$. martiana observou-se uma a duas camadas de células paliçádicas alongadas, esta característica pode ser uma estratégia adaptativa utilizada pela espécie para utilizar o máximo de luz como já referido por Menezes et al. (2006), uma vez que a mesma é típica de ambientes com elevada incidência luminosa.

O tecido de sustentação foi observado na forma de fibras e esclereídes. As fibras associadas ao sistema vascular foram observadas em todos os órgãos, exceto na raiz, sendo esta característica comum na subfamília Caesalpinioideae (Metcalfe \& Chalk, 1950). Esau (1974) afirmou que a presença de grande quantidade de esclerênquima é comum em plantas xerófitas, servindo como reforço para compensar os danos causados pelo murchamento. As células pétreas ocorreram exclusivamente no pecíolo. A presença destas estruturas confere maior rigidez e resistência ao pecíolo, uma vez que este é uma estrutura de sustentação da folha. Jorge et al. (2006) relataram a presença de células pétreas relacionadas aos feixes vasculares na lâmina foliar de Hymenaea courbaril var. stilbocarpa.

Cristais prismáticos e drusas de oxalato de cálcio foram encontrados em todos os órgãos aéreos. A presença de cristais é uma característica frequente em Detarieae, tribo na qual se encontra o gênero Hymenaea (Zindler-Frank, 1987). Estas estruturas atuam na proteção contra herbívoros, refletem o tipo de solo no qual a planta se encontra, sendo considerados depósitos de produtos de excreção, possivelmente protegendo as células do excesso de cálcio (Cutter, 1986; Zindler-Frank, 1987). Além disso, a transpiração influencia na precipitação destas estruturas (Zindler-Frank, 1987), assim a grande quantidade de cristais encontrados em $H$. martiana pode ser explicada, em parte, à sua exposição a altos níveis de luminosidade e minerais presentes no solo.

Metcalfe \& Chalk (1950) registraram para a subfamília Caesalpinioideae a presença de cristais solitários, principalmente associados às nervuras e cristais em forma de drusas. Esses autores ainda afirmaram que a presença de cristais drusíferos são características que diferenciam Caesalpinioideae das demais subfamílias de Fabaceae, sendo este, portanto, um caráter taxonômico observado na espécie estudada.

Cavidades secretoras ocorrem em todos os órgãos de $H$. martiana. Metcalfe \& Chalk (1950) registraram para Hymenaea a presença de cavidades secretoras de resina. De acordo com Roshchina \& Roshchina (1993), esta resina é uma mistura de substâncias incluindo terpenóides, flavonóides e lipídios, sendo formada como processo normal do metabolismo ou como resposta às injúrias. As funções incluem proteção contra patógenos e animais herbívoros além de atuar na cicatrização, quando a planta sofre algum tipo de ferimento (Cutter, 1986; Roshchina \& Roshchina, 1993).

Grãos de amido estão presentes, com exceção da folha, em todos os órgãos vegetativos, sobretudo no córtex e na medula. Rodrigues \& Machado (2004) afirmaram que a presença de muitos amiloplastos nas células corticais e medulares indica que, nestas regiões, a principal função do parênquima é a de reserva. Infere-se neste trabalho, que o parênquima cortical e medular de $\mathrm{H}$. martiana tem a mesma função observada pelos autores já citados.

$\mathrm{Na}$ epiderme da cavidade secretora foi registrada pouca quantidade de lipídios, este resultado pode indicar que a composição da resina secretada apresenta maior quantidade de terpenos e flavonóides, pois compostos do tipo terpenos já haviam sido registrados em Hymenaea courbaril var. stilbocarpa por Nogueira et al. (2001) e para outras espécies do gênero por Langenheim \& Lee (1974) e Barbosa et al. (2007). Os terpenóides possuem atividades bactericida, fungicida, antiparasitária, inseticida e em muitos vegetais, estimulam a cura de ferimentos (Roshchina \& Roshchina, 1993). Sugere-se que o uso da resina de $H$. martiana como cicatrizante, na medicina popular, no município de Caetité, esteja relacionado à presença dos terpenóides, supondo que a ação destes compostos no organismo humano seja semelhante ao que ocorre nos vegetais.

$\mathrm{O}$ uso da casca e entrecasca do caule de $H$. martiana, pela população de Caetité, no combate às inflamações, pode estar relacionado à presença dos flavonóides, que além de ser componente de resinas (Roshchina \& Roshchina, 1993), também são encontrados em tecidos superficiais e parenquimáticos.

Compostos fenólicos foram encontrados impregnando as paredes das células corticais e floemáticas da raiz, nervura central da folha, e pecíolo. Os flavonóides, são uma das classes de compostos fenólicos registrado em $\mathrm{H}$. courbaril var. stilbocarpa por Barbosa et al. (2007). Zuanazzi \& Montanha (2000) e Alcaraz \& Carvalho (2004) afirmaram que estes metabólitos podem agir como anti-inflamatórios, antivirais, anti-hemorrágicos, antimicrobianos e antioxidantes.

Os resultados obtidos demonstram que $H$. martiana apresenta caracteres anatômicos importantes para a sobrevivência em ambiente com alta luminosidade e escassez de água, tendo cutícula

Rev. Bras. Pl. Med., Botucatu, v.14, n.4, p.673-679, 2012. 
espessa, grande quantidade de cristais e esclerênquima, tricomas tectores, folha hiopoestomática, células paliçádicas alongadas e justapostas, espessamento da parede celular e elevado número de nervação.

A presença de cavidades secretoras de resina e grande quantidade de compostos fenólicos são de grande valor e foram considerados indícios que podem justificar a utilidade medicinal. Levando em conta o uso de $H$. martiana no combate a diversas enfermidades, ressalta-se a necessidade de estudos químicos a fim de identificar a relação entre as substâncias ergásticas encontradas e o uso da espécie, sobretudo, a natureza dos produtos de secreção das cavidades secretoras, os tipos de compostos fenólicos, suas características, e possíveis atividades biológicas, garantindo segurança para as pessoas que usam as plantas medicinais como fonte de tratamento.

\section{AGRADECIMENTO}

Os autores agradecem ao Dr. Luciano Paganucci de Queiroz (UEFS) pela identificação da espécie; à Universidade do Estado da Bahia (UNEB) pela concessão de bolsa de Iniciação Científica à primeira autora e à Fundação de Amparo à Pesquisa do Estado da Bahia (FAPESB) pelo auxílio financeiro (Termo de Outorga PNE 0020/2011).

\section{REFERÊNCIA}

ALQUINI, Y. et al. Epiderme. In: APPEZZATO-DA-GLÓRIA, B.; CARMELLO-GUERREIRO, S.M. Anatomia vegetal. 2.ed. Viçosa: UFV, 2006. p.87-107.

ALCARAZ, M.J.; CARVALHO, J.C.T. Flavonóides como agentes antiinflamatórios. In: CARVALHO, J.C.T. Fitoterápicos antiinflamatórios: aspectos químicos, farmacológicos e aplicações terapêuticas. Ribeirão Preto: Tecmedd, 2004. p.79-100.

BARBOSA, M.P.C. et al. Estudo químico e avaliação de atividade biológica de folhas de Hymenaea courbaril var. stilbocarpa (Heyne) Lee \& Lang. In: REUNIÃO ANUAL DA SOCIEDADE BRASILEIRA DE QUÍMICA, 30., 2007, Águas de Lindóia, Brasil. Resumo... Águas de Lindóia: SBQ, 2007. p.1-2.

BORBA A.M.; MACEDO, M. Plantas medicinais usadas para a saúde bucal pela comunidade do bairro Santa Cruz, Chapada dos Veadeiros, MT, Brasil. Acta Botanica Brasilica, v.20, n.4, p.771-82, 2006.

CUTTER, E.G. Anatomia Vegetal: parte I-Células e tecidos. 2.ed. São Paulo: Roca, 1986. 304p.

ESAU, C. Anatomia das plantas com sementes. São Paulo: Edgard Blucher, 1974. 293p.

JORGE, L.I.F. et al. Exame microscópico de Fícus enormis (Mart. ex Miq.) Miq. (gameleira) e de Hymenaea courbaril L. var. stilbocarpa (Hayne) Lee \& Langenheim (jatobá). Revista Brasileira de Farmacognosia, v.87, n.3, p.85-8, 2006.

LANGENHEIM, J.H.; LEE, Y.T. Reinstatement of the genus Hymenaea (Leguminosae: Caesalpinioideae) in Africa. Brittonia, v.26, n.10, p.3-21, 1974.

LEWIS, G.P. Legumes of Bahia. Kew: Royal Botanic Gardens, 1987. 369p.

MACÊDO, N.A. Manual de técnicas em histologia vegetal. Feira de Santana: UEFS, 1997. 96p.

MENEZES, N.L.; SILVA, D.C.; PINNA, G.F.A.M. Folha. In: APPEZZATO-DA-GLÓRIA, B.; CARMELLO-GUERREIRO, S.M. Anatomia vegetal. 2.ed. Viçosa: UFV, 2006. p.30425.

METCALFE, C.R.; CHALK, L. Anatomy of the dicotyledons. Oxford: Clarendon Press, 1950. v.2, 1500p. MOREIRA-CONEGLIAN, I.R.; OLIVEIRA, D.M.T. Anatomia comparada dos limbos cotiledonares e eofilares de dez espécies de Caesalpinioideae (Fabaceae). Revista Brasileira de Botânica, v.29, n.2, p.193-207, 2006. MORI, S.A. et al. Manual de manejo do herbário fanerogâmico. 2.ed. Ilhéus: CEPLAC, 1985. 97p.

NOGUEIRA, R.T. et al. Clerodane-type diterpenes from the seed pods of Hymenaea courbaril var. stilbocarpa. Phytochemistry, v.58, p.1153-7, 2001.

PASA, M.C.; SOARES, J.J.; NETO, G.G. Estudo etnobotânico na comunidade de Conceição-Açu (Alto da bacia do Rio Aricá Açu, MT, Brasil). Acta Botanica Brasilica, v.19, n.2, p.195-207, 2005.

QUEIROZ, L.P. Leguminosas da Caatinga. Feira de Santana: UEFS, 2009. 467p.

RODRIGUES, T.M.; MACHADO, S.R. Anatomia comparada do pulvino, pecíolo e raque de Pterodon pubescens Benth. (Fabaceae-Faboideae). Acta Botanica Brasilica, v.18, n.2, p.381-90, 2004.

ROSHCHINA, V.V.; ROSHCHINA, V.D. The excretory function of higher plants. Berlin: Spinger-Verlag, 1993. 134p.

SAMBUICHI, R.H.R.; MIELKE, M.S.; PEREIRA, C.E. Nossas árvores: conservação, uso e manejo de árvores nativas no sul da Bahia. Ilhéus: Editus, 2009. $295 p$.

SILVA, A.J.R.; ANDRADE, L.H.C. Etnobotânica nordestina: estudo comparativo da relação entre comunidades e vegetação na Zona do Litoral - Mata do Estado de Pernambuco, Brasil. Acta Botanica Brasilica, v.19, n.1, p.45-60, 2005.

SOUZA, C.D.; FELFILI, J.M. Uso de plantas medicinais na região de Alto Paraíso de Goiás, GO, Brasil. Acta Botanica Brasilica, v.20, n.1, p.135-42, 2006.

ZINDLER-FRANK. E. Calcium oxalate crystals in legumes. In: STIRTON, C.H. (Ed.). Advances in Legume Systematics. Part 3. Kew: Royal Botanic Gardens, 1987, p.279-311.

ZUANAZZI, J.A.S.; MONTANHA, J.A. Flavonóides. In: SIMÕES, C.M.O. et al. (Orgs.). Farmacognosia: da planta ao medicamento. Porto Alegre: UFRGS, 2000. p.577-614. 